\title{
Spatial Changes of Landscape and Urban Planning for the Ethnic Settlements under the Background of Urbanization
}

\author{
Zhe-Feng Lin ${ }^{1}$, Jin-Yao Yang ${ }^{2 *}$ \\ ${ }^{1}$ Graduate Institute of Urban Planning, Taipei University, Chinese Taipei \\ ${ }^{2}$ Zhejiang Changxiang Construction Co., Ltd., Hangzhou, China \\ Email: ^176605973@qq.com
}

How to cite this paper: Lin, Z.-F., \& Yang, J.-Y. (2021). Spatial Changes of Landscape and Urban Planning for the Ethnic Settlements under the Background of Urbanization. Current Urban Studies, 9, 419-433. https://doi.org/10.4236/cus.2021.93026

Received: July 13, 2021

Accepted: August 13, 2021

Published: August 16, 2021

Copyright $\odot 2021$ by author(s) and Scientific Research Publishing Inc. This work is licensed under the Creative Commons Attribution International License (CC BY 4.0).

http://creativecommons.org/licenses/by/4.0/ (c) (i) Open Access

\begin{abstract}
With the stable development of new countryside construction, the changing of the landscape pattern in the Chinese countryside attracts more attention, especially in the ethnic townships which are hardly accessible. To explore the development of ethnic areas, it is crucial to understand the spatial and temporal variation of the landscape pattern. In this study, the landscape pattern change was analyzed at both patch type level and landscape level. The land use data (format: vector) got from Aerla Town (a typical Daur ethnic township in Inner Mongolia) for the duration from 2008 to 2013 was analyzed by ArcGIS platform and Fragstats. For the patch level, the grassland, farmland, and forestland turned into construction land gradually. Regarding the landscape level, the landscape diversity index and landscape connectivity index were relatively low, the heterogeneity index and the landscape fragmentation were relatively high, and the landscape fragmentation index was increasing. Then with considering the social and economic development in Aerla Town, the Pearson correlation analysis and grey correlation method are used to get the main driving force of landscape change. The results indicated that population changes and GDP growth were the main driving forces of landscape pattern change. Finally, the driving forces which resulted in the variation of landscape pattern incorporating the economic, cultural, policy, and natural effects were discussed. The research could provide basic information and a theoretical foundation for the development of minority areas in Northeast China.
\end{abstract}

\section{Keywords}

Ethnic Townships, Urbanization, Landscape Pattern, Driving Force 


\section{Introduction}

In the process of urbanization, China's urbanization rate increased rapidly from $19.4 \%$ in 1980 to $52.6 \%$ in 2012 , and it has been demonstrated that the urbanization process has been far ahead of its economic development (Yang, 2013). The land-use changes caused by urbanization have been regarded as the most important factor that impacts the environment, so the ecological effect of urbanization has gradually attracted public attention (Qi et al., 2013; Xia et al., 2020). Landscape pattern analysis, as the core content of landscape ecology research, can effectively guide landscape planning, design, and management. On one hand, the temporal and spatial changes of the landscape pattern are the basis for studying the driving forces and the impact of urbanization on the socio-economic environment. On the other hand, exploring the changes and driving forces of landscape patterns can reveal the urban landscape ecological status and spatial variation characteristics, and it can also provide an effective way for landscape ecological security evaluation and landscape planning. Analyzing spatiotemporal characteristics of land-use change is essential for understanding and assessing the ecological consequence of urbanization. More importantly, such analysis can provide basic information for appropriate decision-making. For example, Dadashpoor et al. (2019) analyzed land-use change, urbanization and their impact on the change in landscape pattern in Tabriz metropolitan area (TMA) during the period from 1996 to 2016 to provide support sustainable regional planning. Deng et al. (2009) explored the spatio-temporal dynamics and evolution of land-use change and landscape patterns in response to the rapid urbanization process of a booming-developing city in China from 1996 to 2006. As the urbanization of most large cities has been done, recent research has paid more attention to the changing of landscape patterns caused by urbanization for small and medium-sized cities. For example, Huang et al. (2014) conducted a study about landscape pattern change in a small city in Zhejiang Province, China. In addition, some scholars have also researched the changing of landscape patterns in rural areas (Liu et al., 2013). For example, Tan and Li (2013) analyzed the changes in landscape pattern, driving factors and policy perspectives of rural settlements in China. However, at present, most studies only researched the changing of landscape patterns for the cities or villages dominated by Han nationality and paid little attention to changing of landscape patterns in minority areas of China (Meng et al., 2020). It has been demonstrated that the urbanization process will lead to a decline in the diversity of ecological patterns (Grimm et al., 2008; Mckinney et al., 2006), but whether the landscape heterogeneity of the towns that dominated by ethnic minority populations also showed a declined tends, and what is the main driving force for the changing of the landscape pattern in ethnic minority areas still to be resolved. To clarify the driving force and changing trends of landscape patterns for minority areas, this study analyzed the changing of landscape patterns in a typical ethnic minority town named Aerla Town. Based on the land use data of 
the study area from 2008 to 2013, we firstly analyze the changing of landscape patterns in Aerla Town. Then, combined with socio-economic data, a new method named grey correlation model and the typical Pearson correlation method are used to get the driving force factors, respectively. The results of this study could provide a view to revealing the changing laws and driving factors of the landscape pattern of Aerla Town, and could provide a useful way of planning, decision-making for land rational use in Aerla Town. It can also serve as a useful reference for the development of ethnic minority townships in Northeast, China.

\section{Research Area and Methods}

\subsection{Overview of the Research Area}

Aerla Town $\left(48^{\circ} 28^{\prime} \mathrm{N}, 124^{\circ} 30^{\prime} \mathrm{E}\right)$ belongs to the Moridawa Daur Autonomous Banner, Inner Mongolia, and is located in the northwest of Moridawa Daur Autonomous Banner and the northeast of the Inner Mongolia Autonomous Province (Figure 1). The town is located on the east bank of the Nuomin River. The study area belongs to a mid-temperate continental monsoon climate, with an average annual frost-free period of 115 days. The average temperature of the study area is $1.3^{\circ} \mathrm{C}$, and the annual precipitation of the study area is 400 to $500 \mathrm{~mm}$. The town has a total area of $374 \mathrm{~km}^{2}$. The cultivated area is about $14,866 \mathrm{hm}^{2}$, the pasture area is about $10,000 \mathrm{hm}^{2}$, and the forest-covered area is $5333 \mathrm{hm}^{2}$. The town has a total of 11 administrative villages (including 8 Daur villages), with a total population of 7980 . The agricultural population is about 6950 , and
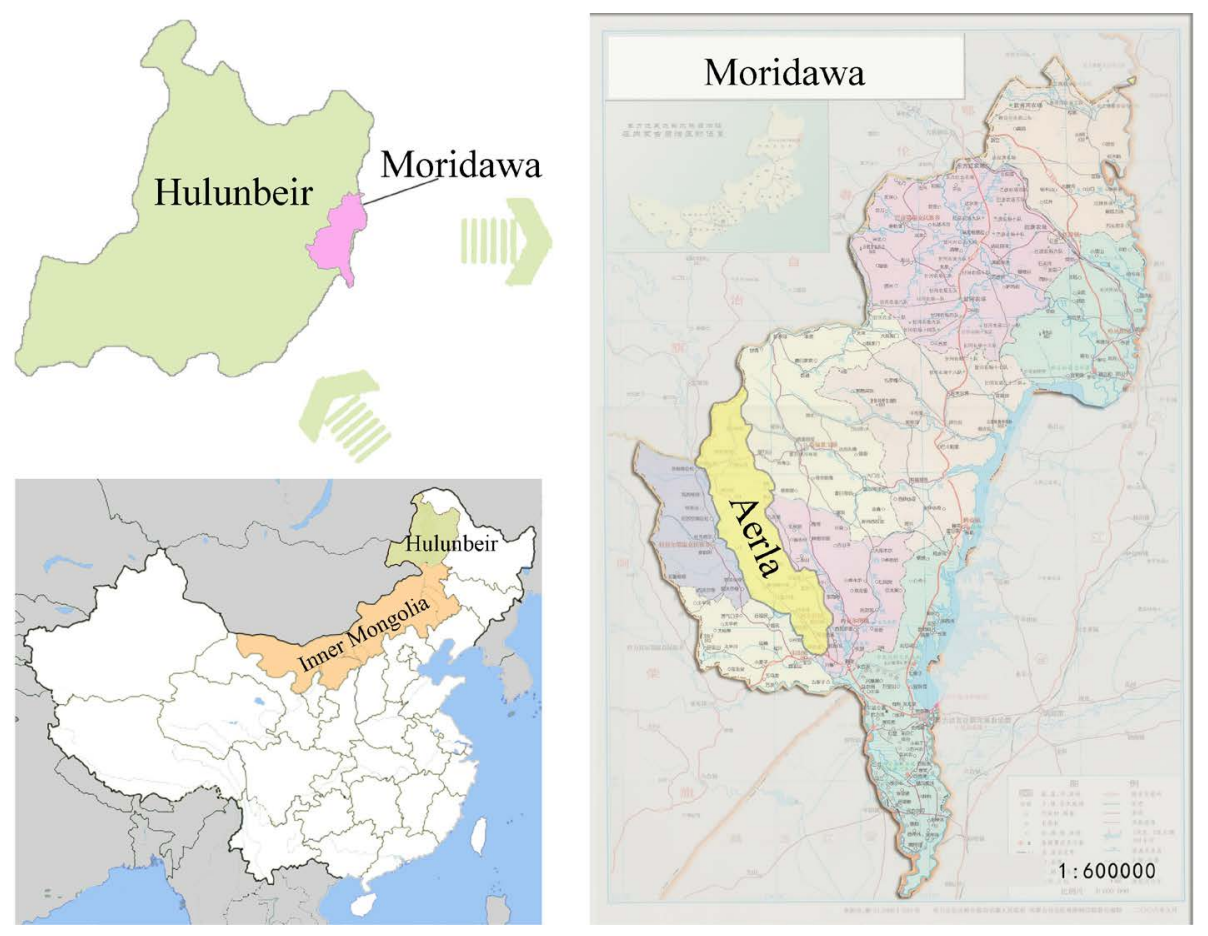

Figure 1. The location of the study area. 
a minority population of 4663 , accounting for $58.4 \%$. The town is rich in natural resources and public transportation is convenient. Aerla Village, where the town government is located, is $43 \mathrm{~km}$ away from Nierji Town and $12 \mathrm{~km}$ away from National Highway 111.

\subsection{Data Sources and Processing}

The used data in this study include the land using data of Aerla town between 2008-2013 and the corresponding socio-economic data. We got the land using data from the Land and Resources Bureau of Moli Daur Autonomous Banner. The resolution of the land using data is $2.44 \mathrm{~m}$. The corresponding socio-economic data derived from the Statistical Yearbook of Morida Wadaur Autonomous Banner. The ArcGIS 10.1 software was used to identify, process and re-categorize the land use data of Aerla Town in 2008, 2010, 2011, 2012 and 2013, then land-use vector diagram of Aerla Town within the five years is obtained. Based on the spatial Analysis extension module under the ArcGIS platform, the data in vector format was converted into the land-using raster map in raster format. Then the Fragstats 4.0, a landscape pattern analysis software was used to calculate the corresponding landscape index to complete the analysis of landscape pattern changing. Finally, according to the results of the landscape pattern changing and corresponding socio-economic data, the typical Pearson correlation analysis and a new model named grey correlation analysis were used to judge the driving force factors of the landscape pattern evolution in Aerla town and reveal the internal motivation of the evolution trend of ethnic rural settlements.

\subsection{The Classification of Land Use Types}

Based on the specific conditions of the ethnic regions and the purposes of this study, the visual interpretation results of land use in Aerla town include mining land, villages, scenic spots and special land, road land, shrubland, orchard, dry land, river water, lake water, pond water, bare land, artificial pasture grassland, natural pasture grassland, forest land, and facility agricultural land. Regarding the Standard Regulations for Classification of Land Use Status, the land use types in the study area are classified into six types: farmland, forestland, grassland, construction land, water area, and unused land (Figure 2).

\subsection{Selection of Landscape Pattern Index}

Based on the results of the previous study and the specific conditions of the study area (Li \& Liu, 2017; Cialdea \& Privitera, 2021), for the patch level, seven indicators including patch area (CA), patch area percentage (PLAND), patch density (PD), patch number (NP), average patch area (AREA_MN), average patch fractal dimension (FRAC_MN) and aggregation index (AI) were selected to evaluate the changing of the landscape patterns. For the landscape level, four indicators including Shannon diversity index (SHDI), Shannon evenness index (SHEI), contagion index (CONTACT), and aggregation index (AI) were used to assess the 


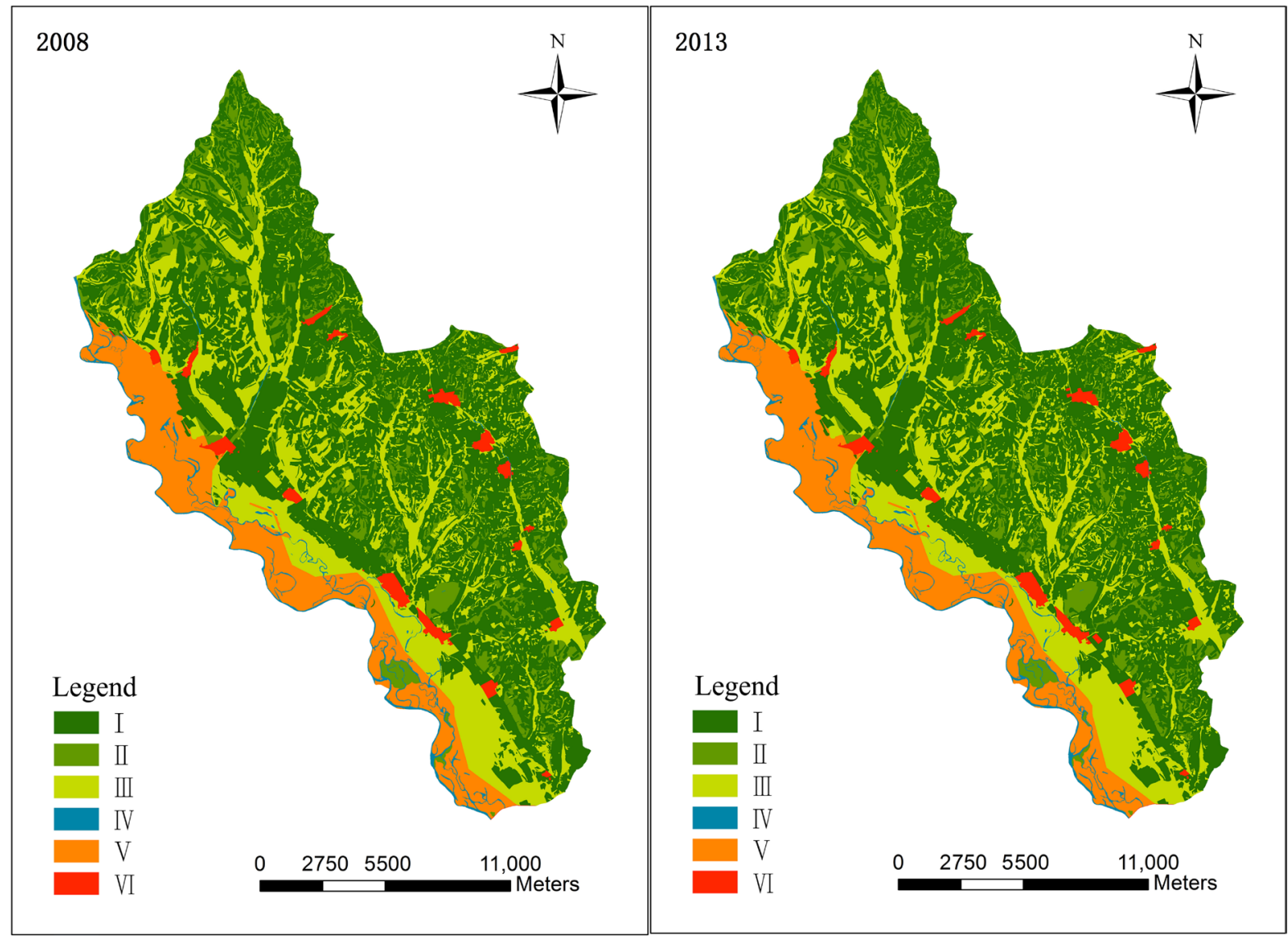

Figure 2. Land use maps of Aerla in 2008 and 2013. I: Farmland; II: Forestland; III: Grassland; IV: Water; V: Unused land; VI: Construction land.

diversity and heterogeneity of landscape patterns.

\section{Results}

\subsection{The Main Characteristics of Each Patch Type}

Table 1 shows the main characteristics of each patch type in Aeral town. As we can be seen from Table 1, the land type with the largest area in Aerla Town is farmland, which accounts for about $52 \%$ of the total area in the study area. The second is grassland and unused land. Between 2008 to 2013, the farmland, forestland and grassland are in a slowly decreasing trend, while construction land has a certain increasing trend, but the overall change is not significant. Based on the aggregation index and average patch fractal dimension, the unused land has the highest degree of aggregation, and the fractal dimension is also the largest. It indicates that the unused land is relatively concentrated, but the shape is irregular. The unused land mainly refers to the undeveloped area along the river beach, which is still in a relatively primitive state. The aggregation index of farmland and construction land is relatively high. It means that the distribution of the farmland and construction land is relatively concentrated. The concentration of forestland and grassland is at a medium level, and the water area is at the 
Table 1. Landscape metrics at patch level from 2008 to 2013 in Aerla.

\begin{tabular}{|c|c|c|c|c|c|c|c|}
\hline $\begin{array}{l}\text { Type level } \\
\text { index }\end{array}$ & Year & Farmland & Forestland & Grassland & $\begin{array}{l}\text { Construction } \\
\text { land }\end{array}$ & Water & $\begin{array}{c}\text { Unused } \\
\text { land }\end{array}$ \\
\hline \multirow{5}{*}{$\begin{array}{c}\text { Patch area } \\
(\mathrm{CA}) \\
\left(\mathrm{hm}^{2}\right)\end{array}$} & 2008 & $18,104.46$ & 2986.84 & 8270.63 & 669.69 & 594.21 & 3976.89 \\
\hline & 2010 & $18,094.80$ & 2986.84 & 8270.63 & 679.35 & 594.21 & 3976.89 \\
\hline & 2011 & $18,094.80$ & 2986.84 & 8270.63 & 679.35 & 594.21 & 3976.89 \\
\hline & 2012 & $18,093.05$ & 2985.96 & 8268.00 & 684.61 & 594.21 & 3976.89 \\
\hline & 2013 & $18,093.05$ & 2985.96 & 8268.00 & 684.61 & 594.21 & 3976.89 \\
\hline \multirow{5}{*}{$\begin{array}{c}\text { Patch area } \\
\text { percentage } \\
\text { (PLAND) } \\
(\%)\end{array}$} & 2008 & 52.3 & 8.6 & 23.9 & 1.9 & 1.7 & 11.5 \\
\hline & 2010 & 52.3 & 8.6 & 23.9 & 2.0 & 1.7 & 11.5 \\
\hline & 2011 & 52.3 & 8.6 & 23.9 & 2.0 & 1.7 & 11.5 \\
\hline & 2012 & 52.3 & 8.6 & 23.9 & 2.0 & 1.7 & 11.5 \\
\hline & 2013 & 52.3 & 8.6 & 23.9 & 2.0 & 1.7 & 11.5 \\
\hline \multirow{5}{*}{$\begin{array}{c}\text { Patch } \\
\text { number (NP) }\end{array}$} & 2008 & 81 & 431 & 730 & 26 & 257 & 6 \\
\hline & 2010 & 81 & 431 & 730 & 27 & 257 & 6 \\
\hline & 2011 & 81 & 431 & 730 & 27 & 257 & 6 \\
\hline & 2012 & 81 & 431 & 731 & 27 & 257 & 6 \\
\hline & 2013 & 81 & 431 & 731 & 27 & 257 & 6 \\
\hline \multirow{5}{*}{$\begin{array}{c}\text { Patch density } \\
\text { (PD) } \\
\left(\mathrm{No} \cdot \mathrm{hm}^{-2}\right)\end{array}$} & 2008 & 0.23 & 1.25 & 2.11 & 0.08 & 0.74 & 0.02 \\
\hline & 2010 & 0.23 & 1.25 & 2.11 & 0.08 & 0.74 & 0.02 \\
\hline & 2011 & 0.23 & 1.25 & 2.11 & 0.08 & 0.74 & 0.02 \\
\hline & 2012 & 0.23 & 1.25 & 2.11 & 0.08 & 0.74 & 0.02 \\
\hline & 2013 & 0.23 & 1.25 & 2.11 & 0.08 & 0.74 & 0.02 \\
\hline \multirow{5}{*}{$\begin{array}{c}\text { Average } \\
\text { patch area } \\
(\text { AREA_MN) } \\
\left(\mathrm{hm}^{2} \mathrm{No}^{-1}\right)\end{array}$} & 2008 & 223.51 & 6.93 & 11.33 & 25.76 & 2.31 & 662.81 \\
\hline & 2010 & 223.39 & 6.93 & 11.33 & 25.16 & 2.31 & 662.81 \\
\hline & 2011 & 223.39 & 6.93 & 11.33 & 25.16 & 2.31 & 662.81 \\
\hline & 2012 & 223.37 & 6.93 & 11.31 & 25.36 & 2.31 & 662.81 \\
\hline & 2013 & 223.37 & 6.93 & 11.31 & 25.36 & 2.31 & 662.81 \\
\hline \multirow{5}{*}{$\begin{array}{c}\text { Average } \\
\text { patch fractal } \\
\text { dimension } \\
\text { (FRAC_MN) }\end{array}$} & 2008 & 1.03 & 1.05 & 1.04 & 1.05 & 1.03 & 1.08 \\
\hline & 2010 & 1.03 & 1.05 & 1.04 & 1.05 & 1.03 & 1.08 \\
\hline & 2011 & 1.03 & 1.05 & 1.04 & 1.05 & 1.03 & 1.08 \\
\hline & 2012 & 1.03 & 1.05 & 1.04 & 1.05 & 1.03 & 1.08 \\
\hline & 2013 & 1.03 & 1.05 & 1.04 & 1.05 & 1.03 & 1.08 \\
\hline \multirow{5}{*}{$\begin{array}{c}\text { Aggregation } \\
\text { index } \\
(\mathrm{AI})(\%)\end{array}$} & 2008 & 78.0 & 51.1 & 65.4 & 79.2 & 21.3 & 89.5 \\
\hline & 2010 & 77.9 & 51.1 & 65.4 & 78.9 & 21.3 & 89.5 \\
\hline & 2011 & 77.9 & 51.1 & 65.4 & 78.9 & 21.3 & 89.5 \\
\hline & 2012 & 77.9 & 51.1 & 65.4 & 79.1 & 21.3 & 89.5 \\
\hline & 2013 & 77.9 & 51.1 & 65.4 & 79.1 & 21.3 & 89.5 \\
\hline
\end{tabular}


lowest level. The shape of the water area and grassland is relatively regular, while the forestland shows unregular shapes. The reason for the different shapes between grassland and forestland may be that forestland is less subject to human disturbance, while grassland and waters may be disturbed by humans activities, such as the influence of grazing. Overall, the agglomeration of farmland, construction land and forestland shows a declined trend, while the grassland has an upward trend, and the water and free land do not show a significant change. At the same time, the fractal dimensions of all patches are between 1.03 and 1.08, indicating that the shapes of various types of patches are relatively regular and simple.

\subsection{Landscape Fragmentation}

The patch density, number of patches, and average patch area can be used to measure the fragmentation of landscape types. The large values of patch density and the small values of the average patch area mean the high degree of fragmentation. From Table 1, it can be seen that the land type with the largest number of patches in the study area is grassland, and the descending order is forestland > water area $>$ farmland $>$ construction land $>$ unused land. From the perspective of patch density, the values of grassland are the largest, followed by forestland, then water area $>$ farmland $>$ construction land $>$ unused land. From the perspective of average patch density, grassland, forestland, construction land, and water are all at a low level (all smaller than 30 ), while farmland and unused land are at a higher level (above 200).

In summary, both the number of patches and the values of patch density for grassland is the largest (double times of forestland), and its average patch area is at a lower level. Therefore, the land type with the highest degree of landscape fragmentation is grassland, and the values of fragmentation degree for grassland show an increasing trend. For the forestland and water area, the degree of fragmentation is also relatively high, but there is no significant change. In comparison, the average patch area of the unused land is the largest and the patch density is the smallest, indicating that the unused land is relatively complete and there is no change during the study period, showing a relatively stable state.

\subsection{Landscape Diversity and Heterogeneity}

The diversity and heterogeneity of landscape can be evaluated by Shannon diversity index, Shannon uniformity index, spread index and aggregation index. Shannon diversity index could reflect the diversity of landscape patterns. Table 2 shows the distribution of the metrics at the landscape level from 2008 to 2013 in Aerla town. From Table 2, it can be seen that the Shannon diversity index of Arela Town in 2013 was 1.28, Compared with the average diversity index of North China (the value is 1.63), the landscape diversity level of Arela Township was lower and the types of the patch were relatively simple. The value of the Shannon uniformity index is generally between 0 to 1 , the small values of the uniformity index 
Table 2. Landscape metrics at landscape level from 2008 to 2013 in Aerla.

\begin{tabular}{ccccc}
\hline Year & CONTAG & SHDI & SHEI & AI (\%) \\
\hline 2008 & 43.6284 & 1.2872 & 0.7184 & 73.0283 \\
2010 & 43.5809 & 1.2882 & 0.7189 & 73.0064 \\
2011 & 43.5809 & 1.2882 & 0.7189 & 73.0064 \\
2012 & 43.5752 & 1.2886 & 0.7192 & 73.0155 \\
2013 & 43.5752 & 1.2886 & 0.7192 & 73.0155 \\
\hline
\end{tabular}

mean the distribution of the landscape pattern is uniform. Compared with the average value of landscape uniformity index in North China (the value is about 0.63), the uniformity index of Arela Town in 2013 is about 0.72 , which is slightly higher than the average value, it means that the distribution of the landscape types of Arela Town is uneven. The spread index reflects the degree of connection or continuity of the landscape distribution, and the aggregation index reflects the degree of aggregation of the landscape distribution. From Table 2, it can be found that the value of spread index is about 43 and the value of aggregation index is about 0.72 , which indicating that the spread of the landscape distribution is low, but the degree of aggregation is high, showing a situation of poor connectivity and continuity From 2008 to 2013, there is no evidenced change for both the aggregation index and the spread index, which indicates that the aggregation of the landscape pattern is stable.

\subsection{Driving Forces Analysis of Landscape Pattern Changes}

Based on the results of the previous study and the characteristics of the study area (Luo et al., 2020; Schneeberger et al., 2007), the patch area of each landscape type is selected as the dependent variable. Five indicators including population, GDP, the gross output of agriculture \& farming, the gross output of grain, and the amount of livestock on hand are used as independent variables. Then the Pearson correlation analysis and a new model named grey correlation analysis are used to describe the impact of selected factors on the driving force of landscape patterns

\subsubsection{Pearson Correlation Analysis}

Table 3 shows the results of Pearson correlation analysis between patch area and socioeconomic data in Arela town from 2008 to 2013. From Table 3, it could be found that there is a negative correlation between the patch area of farmland and the gross output of grain. A negative correlation also exists between the patch area of farmland and the gross output of agriculture, GDP, the amount of livestock on hand. In the contrast, there is a positive correlation with the total population. The patch area of construction land has a negative correlation with the total population, and a positive correlation with GDP, the gross output of agriculture, and the amount of livestock on hand. The patch area of waters and unused land is relatively weakly affected by socio-economic factors, and there is no 
Table 3. Correlation coefficient between landscape types and socioeconomic data in Aerla from 2008 to 2013.

\begin{tabular}{|c|c|c|c|c|}
\hline Data of social and economic & Farmland & Forestland & Grassland & Construction land \\
\hline Total population & 0.912 & 0.807 & 0.807 & -0.972 \\
\hline GDP & -0.909 & -0.789 & -0.789 & 0.964 \\
\hline Gross output of Agriculture \& Farming & -0.958 & -0.718 & -0.718 & 0.979 \\
\hline Gross output of grain & -0.975 & -0.632 & -0.632 & 0.967 \\
\hline Amount of livestock on hand & -0.951 & -0.741 & -0.741 & 0.981 \\
\hline
\end{tabular}

significant correlation.

From 2008 to 2013, the area of farmland decreased significantly, with a decrease of $11.41 \mathrm{hm}^{2}$, and the area of forestland and grassland decreased by 0.88 and $2.63 \mathrm{hm}^{2}$, respectively. The area of construction land increased by $14.92 \mathrm{hm}^{2}$. From the Pearson correlation analysis, the reduction of farmland area has a negative correlation with economic development, with a correlation coefficient of 0.909 . The reduction of grassland and forestland also showed a negative correlation with economic development and the correlation coefficient is 0.789 . Only construction land has a positive correlation with economic development, and the correlation coefficient is 0.964 .

From Table 3, it also could be found that, with the improvement of the economy in Aerla Town, there has been a decrease in farmland, forestland and grassland. Although the area of farmland has decreased, the gross output of grain has shown an upward trend, indicating that the efficiency of farmland production capacity in Aerla Town has been improved. There is a negative correlation between the area of farmland and GDP, the amount of livestock on hand. It indicates that with the development of economy and husbandry, the reduction of farmland may be caused by the occupation of farmland and overgrazing. There is a positive correlation between GDP and construction area, indicating that economic development has promoted the expansion of buildings, and at the same time, people's requirements for housing also have been further increased. There is a negative correlation between farmland area and building area. It maybe indicates that there is a phenomenon of construction land occupying farmland land. However, it should be noted that the total population has a significant negative correlation with construction land. It means that the construction showed an increasing trend with the decrease of population, which may lead to the emergence of a certain number of idle houses.

In summary, there is a linear correlation between the changing of each type of patch area and multiple sets of socio-economic indicators. However, it should be noted that the Pearson correlation analysis can only summarize the pairwise correlation between the driving force factors and the types of the patch, and does not consider the comprehensive impact of the 5 sets of socio-economic data on the changing of the patch area. From Table 1, it is found that the changing of 
patch areas is not linearly related to only a set of socio-economic indicators. The changing of patch areas is often affected by multiple influencing factors. Therefore, we further adopt a new method named the grey relational analysis to jointly analyze and verify the comprehensive correlation between the driving force factors and the types of landscape.

\subsubsection{Gray Correlation Analysis}

Gray system refers to a part of the information known and partly unknown system (Kuo et al., 2008). As a branch of the grey system, the grey correlation analysis method is a method to determine the degree of correlation between variables by comparing the overall trend of changes between variables and especially suitable for the systems with small data samples. It has been demonstrated that the evolution of landscape pattern is often controlled by multiple factors, while the Pearson correlation analysis can only summarizing the pairwise correlation between the driving force factors and landscape, without considering the comprehensive effect of social-economic data, it is easy to induce the inaccurate results of the landscape driving force analysis. Therefore, the grey correlation analysis method is used to comprehensively consider the relationship between the economic data and the changing of the patch area to determine the main driving force and lead the driving force analysis more clear and scientific.

The results of the grey correlation analysis are shown in Table 4. The larger value of the coefficient means the stronger relationship between the social-economic data and changing of the patch. It can be seen from Table 4 that, considering the comprehensive effect of the five groups of social-economic indicators, the changing of patch area has a more significant correlation with the total population and GDP. The changing of the patch area is significantly impacted by the dual effects of the total population and GDP. The order of the degree of correlation for different landscape types is: 1) Farmland: total population > GDP > gross output of grain $>$ gross output of agriculture \& farming $>$ amount of livestock on hand; 2) Forest land: GDP > total population > gross output of grain $>$ gross output of agriculture \& farming $>$ amount of livestock on hand; 3) Grassland: total population $>$ GDP $>$ gross output of grain $>$ gross output of agriculture \& farming $>$ amount of livestock on hand; 4) Construction land: GDP $>$ total population $>$ gross output of grain $>$ gross output of agriculture \& farming $>$

Table 4. Grey correlation analysis of driving forces in Aela town from 2008 to 2013.

\begin{tabular}{ccccc}
\hline Data of social and economic & Farmland & Forestland & Grassland & $\begin{array}{c}\text { Construction } \\
\text { land }\end{array}$ \\
\hline Total population & 0.8643 & 0.9341 & 0.995 & 0.9075 \\
GDP & 0.7829 & 0.959 & 0.892 & 0.9905 \\
Gross output of Agriculture \& Farming & 0.6708 & 0.5936 & 0.6164 & 0.5846 \\
Gross output of grain & 0.7128 & 0.6299 & 0.6548 & 0.6201 \\
Amount of livestock on hand & 0.3465 & 0.3386 & 0.3411 & 0.3375 \\
\hline
\end{tabular}


amount of livestock on hand.

Through the analysis of grey correlation, it can be found that the ranking of the driving force that influences the area of patches are similar. Except for the main influencing factors: the total population and GDP. The other influencing factors are ranked in the same order, indicating that the gross output of grain and gross output of agriculture \& farming also has a certain impact on the changing of the patch area, while the impact of livestock stocks is small. It means the impact of newly built pens or overgrazing on the landscape pattern changes can be ruled out. Compared with the effect of gross output of agriculture \& farming, the correlation between patch area and gross output of grain is more relevant. While the patch area of farmland is shrinking, the gross output of grain has increased, indicating that the grain output per unit area has increased and the level of agricultural technology has been advanced. In addition, the increase in grain output will also promote the construction of farmhouses, so the correlation between grain output and construction land is also worthy of attention.

From Table 4, it also could be found that the landscape types which most strongly affected by the total population are farmland and grassland, indicating that the patch area of farmland and grassland is directly related to the changing of population, which is more consistent with the results of the Pearson correlation analysis. The results of grey correlation analysis show that the main factor affecting the changing of the grassland patch area is the total population, while the amount of livestock on hand does not have a significant impact on the changing of grassland area, indicating that the overgrazing caused by the increase in the amount of livestock is not the main reason for the decrease of grassland area. The higher degree of grassland fragmentation is mainly caused by the increase in population.

\section{Discussion}

\subsection{The Evolution Characteristics of the Landscape Pattern in Aerla Town}

Based on the land-using map, the characteristics and changes of the landscape pattern of Aerla Town, a typical Daur rural settlement are analyzed. The landscape pattern of the study area has the following characteristics: The main landscape pattern in Aerla town is farmland. In the process of urban development, there are phenomena of construction land occupying farmland, grassland, and forestland. Farmland, grassland, and construction land are most affected by human activities. Overall, the value of the landscape diversity index for Aerla town is low. The landscape heterogeneity is relatively high, the connectivity is low, the shape of the patch is relatively regular, and the structure is fragmented. However, as the urbanization process of Aral town is slow, the landscape pattern has not changed significantly. No irreparable damage has been caused. However, according to the evolution trend of the landscape pattern, the integrity and continuity of the ecosystem will be threatened under the influence of rapid urbanization. 


\subsection{Driving Factors Analysis for the Landscape Pattern Evolution}

The most important driving forces for the change in landscape pattern in the study area are population and GDP, followed by gross grain output, the gross output of agriculture \& farming. The amount of livestock on hand has the least impact on the landscape pattern changing. Under the dual impact of GDP and population changes, it has led to the decreasing of farmland, forestland, and grassland. The results of the grey correlation method show that grassland degradation is not induced by overgrazing. At the same time, forestland and GDP are negatively correlated, indicating that there is a phenomenon of GDP growth based on the premise of sacrificing the ecological environment. In addition, the change in the grassland patch area is negatively correlated with the population. The increase in population is the main reason for the high degree of grass fragmentation, which will cause the fragmentation of Aerla Town to increase.

The increase in the gross grain output and gross output of agriculture \& farming means the improvement of people's living standards. As a result, people began to encroach on land by themselves. The area of patches related to agriculture is still slowly decreasing. Construction land has increased with the increase of GDP, indicating that the improvement of people's living standards has increased the demand for buildings. Due to the close distance between farmland and construction land, the reduction of farmland is the most serious. While the construction area is increasing, the population is slowly decreasing, which directly leads to an increase in the number of idle houses in the study area. This is also consistent with the field phenomenon that many local "old houses" are idle and unattended.

\subsection{Outstanding Problems under the Effects of Urbanization}

The improvement of economic level has a direct effect on the improvement of people's living standards in ethnic areas. Advanced technology has also brought a "big harvest" for agricultural output. However, it also induces the unbalanced development between material life and spiritual life for ethnic groups. The people in the ethnic region cannot handle the relationship between development and environmental protection well, which has caused a series of ecological and environmental problems. In terms of policy, rural management has separated from the protection of the traditional culture for the Daur ethnic group. The government only considers the performance of the economic development indicators, ignoring the supervision of the land using. As a result, people are driven by unilateral interests to destroy farmland and forestland. The management of agricultural land is also disorderly. The phenomenon of "hollow villages" and the occupation of cultivated land to build houses are prominent. All these have repeatedly increased the contradiction between environmental protection and development.

In terms of culture, the changing of main living types induces that the people in Aeral town gradually abandon the grazing and focus on farmland planting. With the development of the economy, the increasing demand for housing will 
also lead to the arbitrary occupation of farmland. Most Daur people's primitive worship of grasslands has gradually disappeared. The traditional ethnic ecological concept of the Daur has been severely challenged. As the cultivated land can meet their daily needs, many minority residents in the Arla town have gradually developed a mentality of relying on the sky for food and sticking to conventions. Coupled with the insufficient training and guidance of the spiritual civilization of the residents, the overall cultural level of local ethnic minority residents is not high, and the lack of talents related to land use and urban planning is also more likely to lead to blind development and chaotic construction.

Naturally, Aerla Town is located in the northeast of China, and the frost-free period is relatively short. The autumn frost has started in September. Therefore, "winter leisure" is a common and special social phenomenon that has long existed in the lives of farmers in Northeast China. This life type leads to the lack of enterprising spirit for residents and produces an instinctive guard against unfamiliar things. This value orientation has not only caused the overall development of Arla Town to be slowed down and the landscape pattern has not changed significantly, but also due to the backward development, it is easier to lead to weak ecological awareness and the decline of the ecological environment.

\section{Suggestion and Discussion}

Based on the above problems, the following suggestions are put forward: 1) The study area should make full use of the advantages of existing agriculture resources, comprehensively consider the protection of natural environment such as grassland, forestland, water area, increase the exchange of organisms between patches, form an effectively ecological green corridor, improve the existing environment, and enhance its environmental advantages. 2) Protect arable land, strengthen government supervision, and rationally use land resources. Under the premise of protecting various patch types, making full use of the surrounding areas on the barren hills and wasteland to build a new ethnic community with complete infrastructure and ethnic characteristics. It not only could meet the people's increasing housing needs but also avoid the chaotic occupation of new buildings. 3) Strengthen education, improve the overall cultural level and ecological awareness of ethnic minority people, and arouse the conscious concept of protection and inheritance of the people of this ethnic group. Providing an effective theoretical basis for establishing a good landscape distribution and accelerating the process of urbanization in ethnic minority areas.

At the same time, there are also some limitations to this study. The main limitation is that the land using data of Aerla town between 2014-2019 and the corresponding socio-economic data is missing. The reason is that the local government do not collect the land using data between 2014 to 2019. So, it will be difficult to add the land using data about 2014-2019. The authors will try to conduct the corresponding research in future. 


\section{Conclusion}

This paper analyzes the landscape pattern and driving forces of a typical ethnic minority town in Northeastern, China, to understand the potential landscape dynamics and socio-economic development of ethnic minority townships in the process of urbanization. The results show that: The overall landscape pattern of Aerla Town has not changed significantly, and the urban development is relatively lagging. This situation can reflect the outstanding problems in the development of many ethnic minority towns in Northeast China. That is, for the changing of landscape pattern, the GDP and population are still the most dominant factor that affects the changing of landscape pattern, and the changing of traditional culture also has a great influence on its development. People in backward areas have a mental state of eagerness for economic development. Therefore, while pursuing economic development and the improvement of agriculture unilaterally, they have neglected the establishment and cultivation of good ecological awareness and land use awareness. Based on the above problems, several solutions are also suggested.

\section{Conflicts of Interest}

The authors declare no conflicts of interest regarding the publication of this paper.

\section{References}

Cialdea, D., \& Privitera, S. (2021). Landscape Values as a Driving Force to Increase Nature Conservation. Environmental and Planning Policies as a Possible Integration. Sustainable, 13, 6621. https://doi.org/10.3390/su13126621

Dadashpoor, H., Azizi, P., \& Moghadasi, M. (2019). Land Use Change, Urbanization, and Change in Landscape Pattern in a Metropolitan Area. Science of the Total Environment, 665, 707-719. https://doi.org/10.1016/j.scitotenv.2018.11.267

Deng, J. S., Wang, K., Hong, Y., \& Qi, J. G. (2009). Spatio-Temporal Dynamics and Evolution of Land Use Change and Landscape Pattern in Response to Rapid Urbanization. Landscape and Urban Planning, 92, 187-198. https://doi.org/10.1016/j.landurbplan.2009.05.001

Grimm, N. B., Foster, D., \& Groffman, P. (2008). The Changing Landscape: Ecosystem Responses to Urbanization and Pollution across Climatic and Societal Gradients. Frontiers in Ecology and the Environment, 6, 264-272. https://doi.org/10.1890/070147

Huang, L., Yan, L. J., \& Zhao, H. Y. (2014). Landscape Pattern Change of Small City at the Background of Urbanization: The Case of Yueqing City, Zhejiang Province. Huazhong Architecture, No. 11, 90-94. (In Chinese)

Kuo, Y., Yang, T., \& Huang, G. (2008). The Use of Grey Relational Analysis in Solving Multiple Attribute Decision-Making Problems. Computers \& Industrial Engineering, 55, 80 93. https://doi.org/10.1016/j.cie.2007.12.002

Li, Y. F., \& Liu, G. H. (2017). Characterizing Spatiotemporal Pattern of Land Use Change and Its Driving Force Based on GIS and Landscape Analysis Techniques in Tianjin during 2000-2015. Sustainable, 9, 894. https://doi.org/10.3390/su9060894

Liu, Y. S., Lu, S. S., \& Chen, Y. F. (2013). Spatio-Temporal Change of Urban-Rural Equa- 
lized Development Patterns in China and Its Driving Factors. Journal of Rural Studies, 32, 320-330. https://doi.org/10.1016/j.jrurstud.2013.08.004

Luo, Y., Lv, Y. H., Liu, L., Liang, H. B., Li, T., \& Ren, Y. J. (2020). Spatiotemporal Scale and Integrative Methods Matter for Quantifying the Driving Forces of Land Cover Change. Science of the Total Environment, 739, Article ID: 139622.

https://doi.org/10.1016/j.scitotenv.2020.139622

Mckinney, M. L. (2006). Urbanization as a Major Cause of Biotic Homogenization. Biological Conservation, 127, 247-260. https://doi.org/10.1016/j.biocon.2005.09.005

Meng, L. T., Sun, Y., \& Zhao, S. Q. (2020). Comparing the Spatial and Temporal Dynamics of Urban Expansion in Guangzhou and Shenzhen from 1975 to 2015: A Case Study of Pioneer Cities in China's Rapid Urbanization. Land Use Policy, 97, Article ID: 104753. https://doi.org/10.1016/j.landusepol.2020.104753

Qi, Y., Wu, J. G., \& Li, J. L. (2013). Landscape Dynamics of Medium- and Small-Sized Cities in Eastern and Western China: A Comparative Study of Pattern and Driving Forces. Acta Ecologica Sinica, 33, 275-285. (In Chinese)

https://doi.org/10.5846/stxb201111091694

Schneeberger, N., Burgi, M., Hersperger, A. M. et al. (2007). Driving Forces and Rates of Landscape Change as a Promising Combination for Landscape Change Research: An Application on the Northern Fringe of the Swiss Alps. Land Use Policy, 24, 349-361. https://doi.org/10.1016/j.landusepol.2006.04.003

Tan, M. H., \& Li, X. B. (2013). The Changing Settlements in Rural Areas under Urban Pressure in China: Patterns, Driving Forces and Policy Implications. Landscape and Urban Planning, 120, 170-177. https://doi.org/10.1016/j.landurbplan.2013.08.016

Xia, C., Yeh, A. G., \& Zhang, A. Q. (2020). Analyzing Spatial Relationships between Urban Land Use Intensity and Urban Vitality at Street Block Level: A Case Study of Five Chinese Megacities. Landscape and Urban Planning, 193, Article ID: 103669. https://doi.org/10.1016/j.landurbplan.2019.103669

Yang, X. J. (2013). China's Rapid Urbanization. Science, 342, 310. https://doi.org/10.1126/science.342.6156.310-a 